\title{
Atuação do enfermeiro na promoção dos vínculos familiares e desenvolvimento
}

\section{infantil}

Nurse's role promoting family bonds and child development

El papel de la enfermería en la promoción de los lazos familiares y el desarrollo infantil

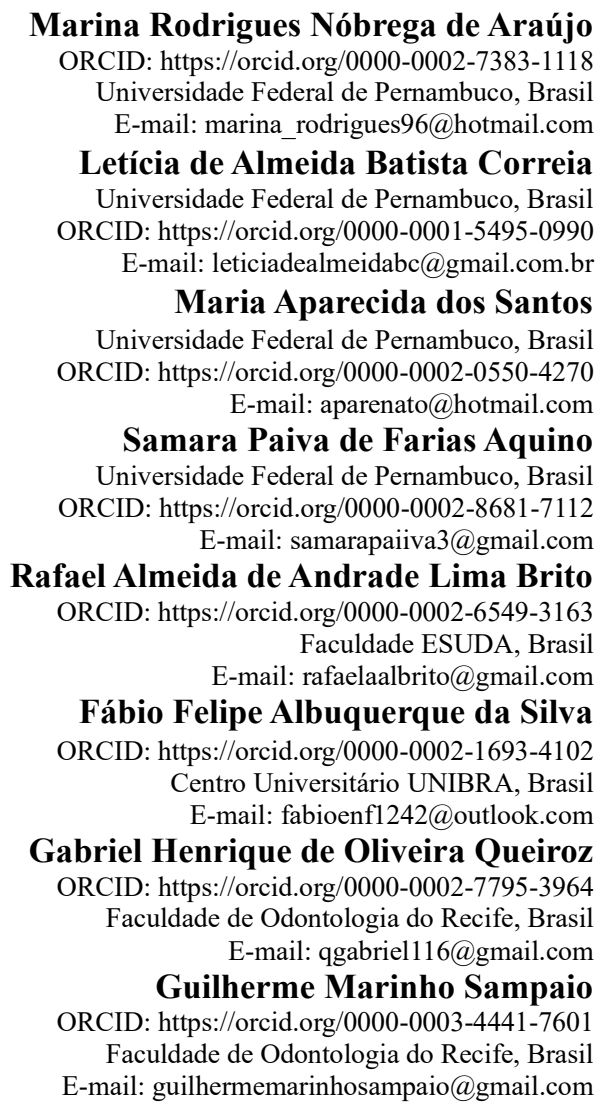

\section{Resumo}

O desenvolvimento da criança é uma transformação contínua e dinâmica, em que o enfermeiro torna-se essencial para os cuidados e orientações que devem ser prestados à família, estimulando práticas positivas para a promoção da saúde e bem-estar infantil. O objetivo deste estudo é compreender a atuação do enfermeiro na promoção de vínculos familiares e desenvolvimento infantil. Métodos: Foi realizado um estudo descritivo e exploratório, com abordagem qualitativa. A coleta de dados foi mediada por entrevistas semiestruturadas, gravadas e posteriormente transcritas, sobre a atuação do enfermeiro na consulta de puericultura voltada à promoção de vínculos familiares e desenvolvimento infantil. Realizou-se com seis enfermeiros de Unidades de Saúde da Família do município do Recife, nos Distritos Sanitários IV e V, de janeiro a março de 2020. Para a análise de dados, utilizouse codificação descritiva linha a linha, gerando códigos agrupados em duas categorias: Atuação do enfermeiro no desenvolvimento infantil e Percepção sobre o cuidado e vínculos familiares. Resultados: Verificou-se a vigilância do crescimento e desenvolvimento em crianças saudáveis de zero a dois anos e a estimulação de interações e práticas parentais positivas entre cuidadores e filhos, desde o pré-natal. O vínculo das equipes com creches e instituições de ensino não é potencializado para a vigilância do desenvolvimento infantil. A percepção sobre os cuidados e vínculos familiares é composta por entraves e fatores intrafamiliares. Conclusão: Os resultados reiteram a necessidade de qualificar os enfermeiros com estratégias criativas de educação permanente, em caráter multidisciplinar, trazendo o protagonismo das crianças e famílias.

Palavras-chave: Enfermagem; Desenvolvimento infantil; Vínculos emocionais.

\section{Abstract}

The child development is a continuous and dynamic transformation, where the nurse becomes essential for the care and guidance that must be provided, encouraging positive practices to promote child health and well-being. The aim of the study is to understand the role of nurses in promoting family bonds and child development. Methods: A descriptive and exploratory study 
with a qualitative approach was carried out. Data collection was mediated by unstructured, recorded and later transcribed, on the role of nurses in childcare consultation aimed at promoting family bonds and child development, with six nurses from Family Health Units in the city of Recife, in the Health Districts IV and V, from January to March 2020. For data analysis, the descriptive line by line is used, generating codes grouped into two categories, addressing the role of nurses in child development and their perception of care and family bonds. Results: Surveillance of growth and development in healthy children aged zero to two years and the stimulation of positive parenting interactions and practices between caregivers and children, from prenatal care, was verified. The teams' link with day care centers and educational institutions is not enhanced for child development surveillance. The perception of care and family bonds is made up of intra-family barriers and factors. Conclusion: The results reiterate the need to qualify nurses with creative strategies for permanent education, on a multidisciplinary basis, bringing children and families to the fore.

Keywords: Nursing; Child development; Emotional bonds.

\section{Resumen}

El desarrollo infantil es una transformación continua y dinámica, en la que el enfermero se vuelve fundamental para el cuidado y orientación que se debe brindar a la familia, fomentando prácticas positivas para promover la salud y el bienestar infantil. El objetivo de este estudio es comprender el papel de las enfermeras en la promoción de los lazos familiares y el desarrollo infantil. Métodos: Se realizó un estudio descriptivo y exploratorio con abordaje cualitativo. La recolección de datos estuvo mediada por entrevistas semiestructuradas, grabadas y posteriormente transcritas, sobre el rol de las enfermeras en las consultas de cuidado infantil orientadas a promover los lazos familiares y el desarrollo infantil. Se realizó con seis enfermeras de Unidades de Salud de la Familia de la ciudad de Recife, en los Distritos de Salud IV y V, de enero a marzo de 2020. Para el análisis de los datos se utilizó codificación descriptiva línea por línea, generando códigos agrupados en dos categorías. Rol de la enfermera en el desarrollo infantil y Percepción del cuidado y lazos familiares. Resultados: Se verificó la vigilancia del crecimiento y desarrollo en niños sanos de cero a dos años y la estimulación de interacciones y prácticas parentales positivas entre cuidadores y niños, desde la atención prenatal. El vínculo de los equipos con las guarderías y las instituciones educativas no se mejora para la vigilancia del desarrollo infantil. La percepción del cuidado y los lazos familiares está formada por barreras y factores intrafamiliares. Conclusión: Los resultados reiteran la necesidad de capacitar enfermeros con estrategias creativas para la educación permanente, de manera multidisciplinaria, poniendo en primer plano a los niños y las familias.

Palabras clave: Enfermería; Desarrollo infantil; Vínculos emocionales.

\section{Introdução}

A evolução histórica da saúde da criança apresentou diversos avanços ao longo das últimas décadas. A assistência de saúde à criança passou por mudanças paradigmáticas do modelo centrado na doença, para um modelo em prol da inclusão familiar e da integralidade do cuidado, através de avanços que refletiram na implantação de diversas políticas públicas de saúde, culminando com a melhora significativa da Atenção à Saúde da Criança. Esta se constitui atualmente como um dos principais focos da Estratégia Saúde da Família (ESF), que tem como responsabilidade, a abordagem integral à criança na fundamentação do seu desenvolvimento, com promoção da qualidade de vida e da equidade (Araújo et al, 2014; Brasil, 2007).

O acompanhamento do crescimento e desenvolvimento é subsidiado pela Caderneta da Saúde da Criança distribuída pelo Ministério da Saúde para todos os nascidos vivos das maternidades públicas, em cumprimento da Portaria $n^{\circ} 158$, de 4 de julho de 2005. Familiares e profissionais de saúde registram e acompanham pontos importantes do crescimento e cotidiano infantil nas consultas periódicas de puericultura. O objetivo básico da assistência da criança pela ESF é contemplar a promoção da saúde infantil, prevenir doenças e educar familiares, através de orientações aos riscos de agravos à saúde e medidas preventivas eficazes (Brasil, 2007).

A Política Nacional de Atenção Integral à Saúde da Criança (PNAISC), de 5 de agosto de 2015, desenvolvida com a intenção de qualificar e orientar ações e serviços de saúde da criança no âmbito nacional, se estrutura em eixos estratégicos que visam a efetivação de medidas que permitam o nascimento e o pleno desenvolvimento na infância, de forma saudável e harmoniosa, bem como a redução de agravos e vulnerabilidades, a prevenção de doenças crônicas na vida adulta e da morte prematura de crianças (Brasil, 2018).

Com efeito, a puericultura contemporânea compreende a criança como um ser em desenvolvimento com suas particularidades, promovendo e protegendo a saúde da mesma através de uma atenção integral. De acordo com a Lei nº 7.498/86, esta prática assistencial foi regulamentada como atividade da consulta de enfermagem, a qual assume o papel relevante em ações 
de promoção de saúde, não só se restringindo ao exame clinico da criança, mas sim prestando assistência sistematizada, de forma global e individualizada, identificando problemas de saúde-doença, executando e avaliando cuidados que contribuam para a proteção e reabilitação de sua saúde. Sua realização envolve uma sequência sistematizada de ações: histórico de enfermagem e exame físico, diagnóstico de enfermagem, plano terapêutico e avaliação da consulta (Campos et al, 2011). O desenvolvimento da criança, conforme Papalia et al. (2000), é uma transformação contínua e dinâmica que inclui, além do crescimento, maturação, aprendizagem, aspectos psíquicos e sociais. Entretanto, é necessário que haja estímulos mediados por pessoas, famílias, profissionais de saúde e da educação para atribuir e delimitar à sua realidade. A interação com os membros da família e com sua rede social de proteção assegura a sua sobrevivência e sua relação com o mundo, contribuindo para o seu desenvolvimento psicossocial e afetivo. Sem o envolvimento desta, as ações que visem às crianças não terão sucesso (Brasil, 2012).

As experiências do início da vida são diretamente influenciadas pela qualidade das relações socioafetivas, principalmente pelas interações estabelecidas com seus cuidadores. No processo de desenvolvimento, a criança necessita de interações positivas e de cuidados adequados, desempenhados por pessoas comprometidas com a sua saúde e bem-estar. Essas pessoas podem ter um papel importante na vida da criança, à medida que se envolvam frequentemente com os seus cuidados e educação. Assim, os vínculos familiares referem-se às relações afetivas que as crianças estabelecem com os seus cuidadores dentro do contexto familiar, possibilitando a base segura para o seu desenvolvimento integral (Abuchaim et al, 2016).

Diante disso, o profissional de saúde tem o papel de orientar os pais em relação à saúde dos filhos, levando em conta todos os aspectos do contexto bio-psico-sócio-cultural. O enfermeiro, por sua vez, atua como um educador, sendo essencial para os esclarecimentos, cuidados e limites que devem ser prestados aos pais, de forma que incentive e estimule as práticas parentais positivas para a promoção da saúde e bem-estar da criança. Uma relação mútua de cooperação com a equipe de saúde e os pais é fundamental para culminar com a promoção do vínculo familiar e, consequentemente, o sucesso do desenvolvimento infantil, impedindo que influências negativas repercutam posteriormente na vida adulta (Brasil, 2015).

Frente a essa conjuntura, verifica-se a necessidade do apoio familiar e seus vínculos afetivos para a construção de uma base segura e desta forma, contribuir para o desenvolvimento infantil integral. Portanto, esse projeto visa destacar a importância da atuação do profissional enfermeiro na promoção dos vínculos familiares e desenvolvimento infantil, e somando-se a isso, compreender a sua vivência através da seguinte questão de pesquisa que norteará o estudo: ‘'Quais as percepções e ações dos enfermeiros na promoção dos vínculos familiares e no processo de desenvolvimento infantil?'’.

\section{Metodologia}

Trata-se de um estudo descritivo, exploratório, com abordagem qualitativa, realizado no município de Recife, em Pernambuco, de janeiro de 2020 a março de 2020. A população alvo da pesquisa foi composta por enfermeiros de cinco Unidades de Saúde da Família (USF), que aceitaram participar voluntariamente da pesquisa. O estudo busca compreender o processo de trabalho dos enfermeiros na promoção de vínculos familiares e desenvolvimento infantil na Atenção Básica, assim como conhecer a rotina profissional do enfermeiro em grupos de gestantes, consultas de puericultura e de grupos educativos com as famílias e suas principais intervenções e analisar as competências e habilidades dos enfermeiros na promoção de vínculos familiares da criança, através dos saberes, instrumentos e educação permanente.

Para Minayo (2008), a abordagem qualitativa aprofunda-se na compreensão dos fenômenos que estuda, interpretandoos segundo a perspectiva dos próprios sujeitos que participam da situação, sem se preocupar com representatividade numérica, generalizações estatísticas e relações lineares de causa e efeito. Assim, destaca-se a objetivação, pois durante a investigação científica é preciso reconhecer a complexidade do objeto de estudo, rever criticamente as teorias sobre o tema, estabelecer conceitos e teorias relevantes, usar técnicas de coleta de dados adequadas e, por fim, analisar todo o material de forma específica e contextualizada. 
A pesquisa foi desenvolvida nas Unidades de Saúde da Família localizadas nos Distritos Sanitários IV e V da cidade do Recife.

Os Distritos Sanitários IV e V foram criados em julho de 1995, como parte do processo de descentralização, sendo uma estrutura organizacional que tem o objetivo de articular ações e serviços de saúde entre os diversos níveis de atenção. Situam-se na parte oeste e norte da cidade, abrangendo um total de 27 bairros e uma população com cerca de 542.725 habitantes (SIAB, 2012).

Os critérios de inclusão da amostra foram enfermeiros que trabalhavam há pelo menos seis meses em Unidades da Saúde da Família nos Distritos IV e V da cidade do Recife e faziam o acompanhamento das crianças nas consultas de puericultura. Foram excluídos do estudo os que estavam de férias ou licença médica.

Após a aprovação ética pelo Comitê de Ética e Pesquisa da Universidade Federal de Pernambuco, sob número de parecer CAAE: 25931919.1.0000.5208, os participantes foram esclarecidos quanto à pesquisa e seus objetivos, solicitados a participarem da mesma e a assinar o Termo de Consentimento Livre e Esclarecido (TCLE).

Como instrumento de coleta de dados, foram utilizados: 1) um roteiro semiestruturado para caracterizar o perfil social e profissional do enfermeiro (idade, quantidade de filhos, estado civil, especialização, outros empregos, tempo de atuação na atenção básica); e 2) entrevista semiestruturada, a qual abordou a atuação na consulta de puericultura voltada para a promoção de vínculos familiares e desenvolvimento infantil.

As principais perguntas norteadoras da entrevista foram: você poderia me explicar sobre a sua atuação nas consultas de puericultura? Como você aborda o desenvolvimento infantil em grupos de gestantes, consultas de puericultura e de grupos educativos? Existe creche/escola ou ação conjunta no território entre equipe USF e instituição de educação? O que você entende por vínculos familiares entre família e criança? Como você percebe a atuação do enfermeiro nessa temática? Quais os principais pontos que você acredita que precisam ser trabalhados para potencializar os vínculos familiares na infância?

As entrevistas foram realizadas pela estudante de graduação em enfermagem orientada pela professora em técnica de coleta, utilizando entrevista semiestruturada. As entrevistas foram agendadas com cada enfermeiro de acordo com dia e horário estabelecidos segundo a disponibilidade dos participantes. As entrevistas foram gravadas utilizando gravador de voz Sony MP3 Linear PCM Recording, de maneira que consistiu em uma melhor compreensão e detalhes das atitudes, valores e motivações em relação aos atores e contextos sociais específicos (Cervo, 2007).

O tempo médio das entrevistas foi de 17 minutos, variando entre o tempo mínimo de 8 minutos e o tempo máximo de 26 minutos. Posteriormente os áudios gravados durante as entrevistas foram transcritos no programa Word da Microsoft.

Realizou-se análise qualitativa dos dados segundo Yin (2016). Os dados foram codificados de forma descritiva, na seleção de trechos. Foram identificados padrões que emergiram a partir dos dados, os quais foram posteriormente agrupados em 12 grupos e posteriormente, originaram duas categorias que foram interpretadas segundo a literatura.

As principais dificuldades encontradas para a realização deste estudo foi encontrar disponibilidade de dia e horário específico do profissional enfermeiro para a realização das entrevistas, visto que a Unidade de Saúde da Família se encarrega de uma alta demanda de atividades. Além disso, em Março de 2020 foi reconhecida uma situação emergencial no Estado de Pernambuco como calamidade pública, decorrente da pandemia da COVID-19, que deu providências correlatas acerca de quarentena e de medidas protetivas, impossibilitando a continuidade das entrevistas em formato presencial nas Unidades de Saúde da Família.

\section{Resultados}

Os participantes foram seis enfermeiros. Destes, a maioria era do sexo feminino, tinham filhos e especialização em Saúde da Família. Somente dois enfermeiros entrevistados relataram ter feito um curso sobre desenvolvimento infantil. Quatro 
dos entrevistados referiram trabalhar em outro local. Em relação à idade, esta oscilou entre 36 e 49 anos. Quanto ao tempo de experiência na Atenção Básica, possuíam de 11 a 21 anos. As informações sobre os enfermeiros estão resumidas abaixo (Quadro $1)$.

Quadro 1: Caracterização dos profissionais entrevistados. Recife, 2020.

\begin{tabular}{|c|c|c|c|c|}
\hline Enfermeiro & Idade & Sexo & $\begin{array}{c}\text { Tempo de Atenção } \\
\text { Básica }\end{array}$ & $\begin{array}{c}\text { Especialização e cursos de } \\
\text { atualização na temática }\end{array}$ \\
\hline 1 & 44 & Feminino & 21 anos & Saúde coletiva \\
\hline 2 & 47 & Feminino & 20 anos & $\begin{array}{c}\text { Saúde da família e Saúde } \\
\text { Pública }\end{array}$ \\
\hline 3 & 45 & Masculino & 14 anos & Saúde da Família e AIDPI \\
\hline 4 & 36 & Feminino & 12 anos & Saúde da Família \\
\hline 5 & 49 & Masculino & 11 anos & Saúde da Família \\
\hline 6 & 40 & Feminino & 17 anos \\
\hline
\end{tabular}

Fonte: Autores.

A partir das entrevistas semiestruturadas, emergiram duas categorias temáticas que retratam os principais códigos: 1) Atuação do enfermeiro no desenvolvimento infantil; 2) Percepção do enfermeiro sobre o cuidado e vínculos familiares.

\section{Categoria 1: Atuação do enfermeiro no desenvolvimento infantil}

Esta categoria aborda a atuação do enfermeiro nas consultas de puericultura, com ênfase nas questões do cuidado à criança, incluindo rotina de acompanhamento, orientações e instrumentos utilizados. Os dados estão resumidos abaixo (Figura $1)$.

Figura 1: Atuação do enfermeiro no desenvolvimento infantil a partir de práticas e conhecimentos. Recife, 2020.

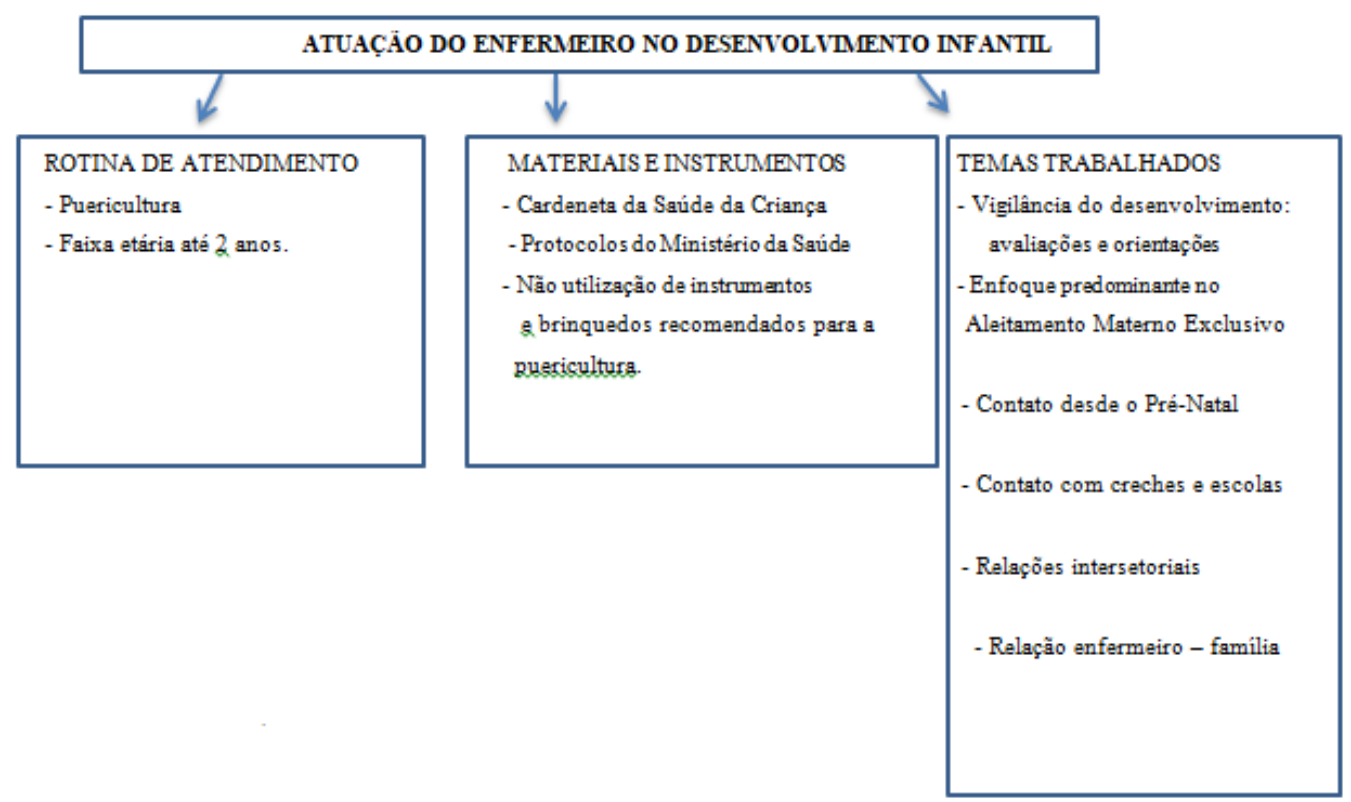

Fonte: Autores. 
Com relação à rotina de atendimento da puericultura, houve semelhanças entre os temas trabalhados nas consultas, acerca da antropometria da criança, higiene, alimentação, cuidados ambientais, vacinas, prevenção de acidentes e estímulos do desenvolvimento. Coincidiram também semelhanças na rotina das USF entrevistadas, com o acompanhamento do enfermeiro na consulta de crianças saudáveis de zero a dois anos de idade.

'Na puericultura eu acompanho o crescimento e desenvolvimento das crianças saudáveis, e as atividades desenvolvidas são orientações em saúde, onde se verifica peso, altura, perímetro cefálico, perímetro torácico e a questão da alimentação para fazer toda a orientação. [...] as orientações mais frequentes são quanto á vacinação, alimentação, higiene e estímulos que devem ser dados ás crianças sobre o desenvolvimento.' (Enfermeiro 1).

'A gente faz a consulta de puericultura a crianças de 0 a 2 anos, tendo como orientações mais frequentes a higiene pessoal, alimentação, vacinas e cuidados ambientais para prevenir acidentes. "' (Enfermeiro 3).

'Se a criança não tiver queixa, se não tiver doença, a gente faz essa consulta do exame físico, orientações sobre a alimentação, vacinação, desenvolvimento e pronto. [...] a gente orienta mais a questão da alimentação, higiene e o desenvolvimento."' (Enfermeiro 4).

'"[...] será agendado a consulta de puericultura com o enfermeiro no primeiro mês, de 0 a 2 anos. Vamos observar se a criança tem algum tipo de doença, identificar se tem alguma má formação, alguma alteração na triagem neonatal, $e$ o desenvolvimento infantil. A antrometria da criança, se o tamanho da cabeça está adequado para idade, se tem alguma alteração ou não. Orientação sobre o aleitamento materno exclusivo [...] ' (Enfermeiro 5).

'Realizo orientações gerais de cuidado, higiene, aleitamento materno exclusivo, introdução da alimentação complementar e estímulos de desenvolvimento." (Enfermeiro 6).

Alguns enfermeiros dão um enfoque predominante no aleitamento materno exclusivo até os seis meses, como um ponto importante de orientação nas consultas, sendo também uma das suas principais dificuldades.

'Hoje a minha orientação mais frequente é o aleitamento materno. A gente está tendo muita dificuldade mesmo na
questão social, as mães estão deixando as crianças com um vizinho ou tia para poder trabalhar. [...] Quando elas vêm
e falam que não estão amamentando, eu pergunto o porquê e elas falam que precisam trabalhar. Minha maior
dificuldade é manter o aleitamento materno exclusivo, uma coisa que era pra ser até os seis meses, mas as crianças
que eu atendo não conseguem nem ficar até 4 meses." (Enfermeiro 2).

'Sempre estimulo o Aleitamento Materno Exclusivo até os 6 meses de idade, enfatizando sua importância para a saúde da criança. ", (Enfermeiro 3).

'As mães aqui não amamentam exclusivamente até seis meses, a maioria, mas já complementam, a gente orienta bastante mas não é uma adesão total." (Enfermeiro 4).

'Eu sempre estimulo este contato com a criança, a questão do aleitamento materno também, para criar este vínculo'” (Enfermeiro 1).

Quanto aos instrumentos utilizados no processo de trabalho, foram citados materiais como a Caderneta de Saúde da Criança, prontuário eletrônico e protocolos do Ministério da Saúde.

'"[...] a gente utiliza o cartão da criança e a gente tem aqui também o prontuário eletrônico, o PEC, que dá várias ferramentas pra a gente utilizar na consulta."'(Enfermeiro 4).

Nenhum deles apontou utilizar brinquedos ou objetos na consulta para avaliar o desenvolvimento. Alguns enfermeiros relataram que perguntam às mães o que não conseguem observar no momento da consulta:

"O instrumento que utilizo é o cardeneta da criança, a qual faço questão de preencher todos os dados; o processo de desenvolvimento, peso, comprimento, perímetro cefálico e mostrar a elas. $O$ que eu não vejo no momento da consulta em relação ao desenvolvimento, sempre pergunto às mães. ' (Enfermeiro 2). 
'Têm coisas que a gente não pode avaliar aqui, então a gente pergunta e dai o relato da família é válido." (Enfermeiro 4).

A Caderneta de Saúde da Criança é utilizada como principal instrumento para avaliar o desenvolvimento da criança e detectar anormalidades, sendo assim avaliada a necessidade de encaminhamentos.

" [...] tendo como instumento os parâmetros da caderneta da saúde da criança. Caso haja alguma alteração, encaminhamos para o pediatra ou outros especialistas, dependendo do caso." (Enfermeiro 3).

'O desenvolvimento da criança é acompanhado pela caderneta da criança de acordo com os marcos esperados da sua idade, assim podendo identificar distúrbios se for anormal." (Enfermeiro 5).

'Na caderneta da criança tem o desenvolvimento saudável para aquela faixa etária, então eu vejo e coloco os marcos e se não estiver tendo aquele acompanhamento, temos o apoio da T.O do NASF para orientar estes estímulos saudáveis." (Enfermeiro 1).

Um dos enfermeiros entrevistados refere que faz rodas de conversas e palestras sobre marcos da infância, utilizando a caderneta da criança para explicar os marcos de desenvolvimento aos pais:

'” A gente já fez rodas de conversas e explicamos os marcos da infância, [...]palestras sobre o assunto, explicando pela caderneta da criança os marcos que a criança tem que ter naquela idade." (Enfermeiro 6).

Um dos enfermeiros acrescenta as potencialidades da caderneta para orientações fornecidas às mães sobre estímulos que podem ser realizados no dia-a-dia da criança.

'Fazemos a avaliação com os testes que a gente acompanha pelo instrumento que o cartão da criança nos fornece, fazendo isso tranquilamente e oriento a mãe, se ela pode colaborar em casa." (Enfermeiro 4).

De acordo com a vigilância do desenvolvimento, alguns enfermeiros abordam avaliações e orientações em comuns, sobre conversas com a criança, estimular brincadeiras entre pais e filhos, não deixar as crianças sozinhas e evitar o uso excessivo de telefones celulares e tablets, promovendo dessa forma o desenvolvimento e cuidados afetivos.

'Eu sempre falo da conversa que os pais devem ter, da criação de vínculo com a criança pra o desenvolvimento adequado, da brincadeira com a criança que deve ter também, e não deixar a criança só lá no cantinho pra as mães irem fazer as atividades domésticas e deixar a criança lá, só em frente á televisão ou então naquilo que virou moda; o tablet ou o celular." (Enfermeiro 1).

'Nas consulta de puericultura enfatizo sempre o cuidado afetivo, as brincadeiras e a conversa entre pais e filhos, estimulando os vínculos." (Enfermeiro 3).

'"[...] falo o que tem que estimular na próxima fase da criança ou se estiver algum marco em atraso, a gente chama atenção sobre como estimular." (Enfermeiro 4).

"Oriento sempre de estar com a criança interagindo, brincando, chamar pelo nome, ensinar os objetos e cores, mostrando. "' (Enfermeiro 5).

' 'É preciso estimular a interação com a criança para o desenvolvimento, estar junto, brincar e não deixar a criança só na televisão e no celular. "' (Enfermeiro 5). 
'Na consulta de puericultura, eu me preocupo muito com a questão do desenvolvimento, a questão da linguagem, psicomotora e cognitiva. [...] Falamos sobre os brinquedos educativos, brinquedos que desenvolvem estímulos, de apertar, que tenha cores e para colocar as crianças sentadinhas para brincar e evitar assistir TV. '” (Enfermeiro 6).

Os entrevistados também mencionam que a estimulação do vínculo familiar e dos cuidados afetivos é feita desde o contato no pré-natal. Uma questão emergida foi o envolvimento dos pais e rede de apoio nestas ações educativas.

\begin{abstract}
'Então, já faço as orientações no período de pré-natal. No pré-natal faço dois encontros: um para trabalhar o aleitamento materno exclusivo e outro para trabalhar crescimento e desenvolvimento. "' (Enfermeiro 2).

'’[...] fazer o acompanhamento do pré-natal, que já é o início de todo o cuidado, com a participação do parceiro, já é um ponto muito importante. E aí a gente já trabalha educação em saúde, não voltados só para as gestantes, mas para os cuidados com o recém-nascido ou lactente." (Enfermeiro 4).

'Para potencializar os vínculos na infância, os cuidados oferecidos tem que ser desde o pré-natal. A gravidez tem que ser planejada e desejada "' (Enfermeiro 5).

"No pré-natal eu sempre peço para que a gestante traga uma pessoa que ela vai poder contar depois que parir. [...] Sempre faço uma questão lúdica para ver se existe envolvimento na família, peço para o pai achar o coraçãozinho da criança na barriga da mãe. Percebo que quando os pais acompanham o pré-natal, tem mais envolvimento, como na questão do aleitamento. [...]'” (Enfermeiro 2).
\end{abstract}

Os enfermeiros entrevistados também referiram possuir um vínculo de equipe USF com creches e instituições de ensino para orientações em saúde e promoção de cuidados com crianças, tendo ações e demandas, em contatos eventuais. Estes espaços não são potencializados na promoção da saúde da criança na perspectiva da vigilância do desenvolvimento.

'[...] toda vez que a creche tem necessidade, elas demandam para a gente. Quando as crianças estão doentes, ela demanda para a gente. Quando tem eventos e orientações de saúde, a gente vai, que é o Programa de Saúde Escolar. "' (Enfermeiro 2).

'’[...] temos uma creche aqui na comunidade que sempre fazemos ação de orientação em saúde, promovendo o cuidado em geral." (Enfermeiro 3).

'No PSE a gente faz o trabalho conjunto com orientações gerais de higiene, cuidados, verminoses, vacinação $e$ desenvolvimento. "' (Enfermeiro 4).

"' Na Saúde na Escola, não fazemos vacinação para as crianças não criarem repúdio, e sim um vínculo. Fazemos palestras com os pais, dando todo o suporte, criando uma abertura para que o vínculo seja o melhor possível. '” (Enfermeiro 5).

''[...] fazemos sempre ações em creche. A equipe de Atenção Básica e da Odonto. Fazemos palestras educativas, vacinação, tendo esse elo com a creche. ' (Enfermeiro 6).

Entretanto, um entrevistado ressalta que a sobrecarga de atividades dificulta ações nas escolas e creches:

“'Não participamos de muitas ações na escola porque o Saúde da Família está muito sobrecarregado. '” (Enfermeiro $5)$.

Entre as relações intersetoriais, alguns enfermeiros relataram encaminhamentos para a terapeuta ocupacional do

NASF.

'[...] se não estiver tendo aquele acompanhamento, temos o apoio da T.O do NASF para orientar estes estímulos saudáveis. "' (Enfermeiro 1). 
'Quando a gente vê que a criança não está desenvolvendo, a gente tem o NASF que nos apoiam com a terapeuta ocupacional. "' (Enfermeiro 4).

'"[...] Unidade de Saúde da Família estar de portas abertas para a mãe e a criança formarem um vínculo, para que sempre necessitar, em conjunto com a nossa equipe e com o NASF. ' (Enfermeiro 5).

Dentre as ações a serem melhoradas, foram apontadas a necessidade de um trabalho intersetorial em conjunto com a saúde, educação, conselho tutelar para a promoção dos vínculos familiares:

'Acho que para potencializar os vínculos familiares teria que ter um trabalho social forte, e não só da parte da saúde, mas também da educação que tem que ser envolvida, escolas, conselhos tutelares, com o intuito de dar orientações. ', (Enfermeiro 3).

Sobre a relação enfermeiro - família, a maioria dos entrevistados reconhece a importância do enfermeiro como profissional que pode melhorar os vínculos familiares, sendo essenciais as orientações educativas e apoio familiar.

"A gente aqui tenta trazer esse vínculo para eles, através das consultas e visitas domiciliares. Sei que temos um papel importante na promoção desse vínculo, [...]'” (Enfermeiro 6).

'O enfermeiro é a peça principal e de extrema importância nessa temática dos vínculos familiares e desenvolvimento da criança, porque é o enfermeiro que acompanha a puericultura para reeducação, [...]' (Enfermeiro 2).

' $O$ enfermeiro faz a orientação à família, de que a criança precisa se inteirar com todos os membros da família, além dos pais, a avó, tio, irmão, mostrando a criança que ela precisa de um vínculo. "' (Enfermeiro 5).

'Sempre incentivo os pais a dar apoio e trabalho muito a questão psicológica também, pois a questão emocional tem que estar equilibrada para poder cuidar de toda uma demanda que uma criança pequena dá dentro de uma casa, pois a infraestrutura da familia interfere muito no cuidado da criança." (Enfermeiro 2).

'Tentamos abordar que a família toda participe, [...]. A gente sabe que existem influências de outras pessoas e ajuda no sentindo do envolvimento. A gente tenta trazer a maior parte da família, quem vive com a criança para as orientações. " (Enfermeiro 4).

'A gente tá sempre trabalhando essa questão do vínculo afetivo entre eles, falando a importância do amor, carinho e estímulo, e não só aquela coisa mecânica." (Enfermeiro 4).

'O vínculo familiar é essencial para o desenvolvimento. Mas tento fazer a minha parte, orientar sempre o estímulo ao desenvolvimento, se dedicar a criança." (Enfermeiro 6).

Esse enfermeiro declara em sua fala a importância do brincar e do ambiente familiar para a formação dos vínculos:

'O brincar com a criança é importante, pois assim ensina a se organizar com o ambiente que ela está. O ambiente é o aprendizado, isso facilita a interação familiar e os vínculos. ' (Enfemeiro 5)

Através dos relatos, foi possível identificar que os vínculos USF/profissionais-família são favorecidos pela abertura que os enfermeiros fornecem, por meio de apoios, ajudas e conversas.

"Os pais se sentem à vontade comigo e sou bem aberto, então conversamos bastante. Não faço julgamentos e eles sempre se abrem comigo, [...]'” (Enfermeiro 3).

' Unidade de Saúde da Família estar de portas abertas para a mãe e a criança formarem um vínculo, para que sempre necessitar, [...]'” (Enfermeiro 5).

" [...] a gente faz uma visita domiciliar logo no início, porque já estreita mais ainda o vínculo com a unidade de saúde, ela se sente apoiada, a família se sente mais segura, a gente oferece apoio e também se precisarem de algo. Outra forma que executo aqui, que еи acho que favorece esse vínculo é está sempre presente, de portas abertas, para qualquer 
dúvida e não necessariamente uma doença, os pais e a família possam vir à unidade para conversar comigo a qualquer momento. "' (Enfermeiro 4)

\section{Categoria 2: Percepção do enfermeiro sobre o cuidado e vínculos familiares}

Esta categoria apresenta a participação da família nos cuidados relacionados ao desenvolvimento infantil e vínculos familiares a partir da percepção dos enfermeiros entrevistados. As falas refletem entraves para a relação entre os enfermeiros e famílias, questões relacionais na família e as dificuldades dos cuidadores em realizar práticas parentais positivas. Os dados estão resumidos abaixo (Figura 2).

Figura 2: Percepção do enfermeiro sobre o cuidado e vínculos familiares relacionados ao desenvolvimento infantil.

Recife, 2020.

\section{PERCEPÇÃO DO ENFERMEIRO SOBRE O CUIDADO E VÍNCULOS FAMILIARES}

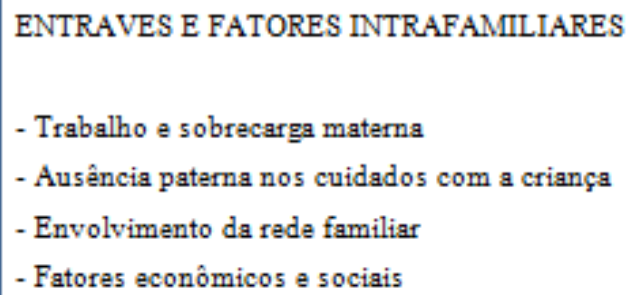

Fonte: Autores.

O trabalho e sobrecarga materna foram problemas recorrentes apresentados pelos enfermeiros, pois o cuidado com a criança muitas vezes é centrado na responsabilidade da mãe e a mesma, contudo, precisa trabalhar, possui afazeres domésticos e ainda tem que dar atenção a outros filhos. Foi identificado dessa forma, que o cuidado com as crianças são delegados também a algum parente ou vizinho, por necessidade da mãe trabalhar.

“[...] as mães precisam trabalhar e deixa o filho com alguma outra pessoa cuidando, essa pessoa pode ser um parente ou um vizinho, ou uma avó." (Enfermeiro 1).

"' A gente está tendo muita dificuldade mesmo na questão social, as mães estão deixando as crianças com um vizinho, a tia para poder trabalhar, a maioria em banca de bicho que não tem nenhum direito garantido." (Enfermeiro 2).

“[...] a criança neste período mais precisa da mãe e ela precisa cuidar da criança, do marido, da casa, do que vai comer hoje, do que vai comer amanhã, [...]' (Enfermeiro 2)

'Na maioria das famílias, as mães são o único suporte. Então, o pai ou outros membros da família ajudam em pequenos momentos. A mãe é provedora de tudo, além da amamentação, está mais próxima da criança.'” (Enfermeiro 5).

'Sei que as mães não têm culpa, pois já têm a casa pra cuidar e não têm dinheiro. Não têm como ainda cuidar dos filhos e dar todo o suporte. $O$ vínculo materno vai além de a mãe estar bem para assim transmitir algo bom para as crianças." (Enfermeiro 6).

O apoio familiar é visto como componente importante a ser incentivado durante as consultas de puericultura: 
'Quando vejo que a mãe não dá conta para cuidar da criança sozinha, sempre peço para ela vir à consulta com alguém que possa ajudar, para conversarmos e melhore no que for possível." (Enfermeiro 3).

Um outro problema apontado, foi a ausência paterna nas consultas de puericultura e no envolvimento com o cuidado.

\begin{abstract}
"Se bem que hoje tem me surpreendido que os pais estão trazendo as crianças, [...] Hoje o envolvimento dos pais está melhor do que antigamente, apesar de ser pouco ainda. "' (Enfermeiro 2).

'Alguns pais por necessidade para sustentar a família, saem de casa de manhã e só voltam á noite; outros por desleixo mesmo, deixam as crianças soltas." (Enfermeiro 3).

'Na maioria das famílias, as mães são o único suporte. Então, o pai ou outros membros da família ajudam em pequenos momentos.' (Enfermeiro 5).

'A gente aqui tenta respeitar, a gente não fica exigindo sempre aqui a presença do pai ou da mãe, embora seja raro o pai vir, e a gente valoriza muito quando eles vêm, ou sozinho ou como acompanhante da mãe. " (Enfermeiro 4).
\end{abstract}

O envolvimento paterno nas consultas seria a melhor forma de melhorar a relação com a mulher e no cuidado com a criança:

\footnotetext{
'Envolver os pais na consulta. Se eles estivessem acompanhando as consultas do pré-natal naquele período, talvez isso melhorasse a relação com a mãe e lógico, com a criança. Se eles se envolvem mais com a criança, eles iam colaborar mais em casa, pois pra maioria deles a mãe que tem que ter a responsabilidade de cuidar da criança." (Enfermeiro 2).
}

Quanto ao envolvimento da rede familiar, os entrevistados apontam a percepção de precariedade de vínculo entre cuidadores-criança, com situações de negligência e violência. As falas relatam a identificação de pouca interação, envolvimento e cuidado dos pais com os filhos. O vínculo familiar é atribuído como uma relação de quem cuida, sendo referido que as relações entre as crianças e os cuidadores podem ficar prejudicadas. 'O vínculo familiar, que pode ser com a mãe ou o cuidador, ou mesmo com a avó. São os vínculos do cuidado, mesmo.
E da atenção que os pais devem ter e muitas vezes, delegam essa função para outras pessoas e não têm aquele vínculo
do cuidado, carinho e atenção." (Enfermeiro 1).

'Tem alguns pais que se percebe pouca interação e envolvimento com os filhos. A gente vê no cuidado, no jeito que se fala com a criança. Tem outros pais que é nítido o amor e o cuidado, tendo a percepção do vínculo familiar. ", (Enfermeiro 3).

' Eu entendo como vínculo entre a família e a criança essa ligação entre quem cuida, quem tá na maior parte do tempo, inclusive quem traz pra as consultas e a criança. "' (Enfermeiro 4).

'Muitas crianças não têm vínculos. O vínculo é algo bem complicado nessa comunidade. Muitas crianças moram com a avó ou os pais deixam com os vizinhos. Eu vejo muito a falta de vínculo entre os pais, muitas vezes no momento da consulta já visualizei momentos de brigas e já até bateram." (Enfermeiro 6).

Durante os relatos, uma questão trazida, foi a comparação dos vínculos familiares existentes da sua família com as famílias da comunidade assistida:

\footnotetext{
'Eu não vejo o vínculo igual que foi comigo quando minha família tinha quando eu era criança e nem o meu vínculo que tenho com meus filhos." (Enfermeiro 6).
} 
Segundo os entrevistados, os fatores econômicos e sociais também divergem no estímulo do cuidado. A vulnerabilidade social e a infraestrutura familiar interferem na atenção à criança, sendo o maior empate para coibir os vínculos familiares. Os enfermeiros acreditam que é preciso um ambiente adequado com condições dignas, alimentação e família estruturada para a transmissão de laços familiares. "O que prejudica muito o estímulo do cuidado são as condições que a família vive, a questão econômica. Por isso eu
tento dar orientações de uma forma que não agridam eles nessa parte socioeconômica, que eles entendam o cuidado
em geral e cuide do filho da melhor forma possível." (Enfermeiro 3).

'Tenho certeza que seria melhor, se tivesse o ambiente bom, sem confusão, com comida em casa. É preciso que família tenha estrutura, condições financeiras, direito ao transporte, dignidade para sustentar vínculos familiares. A criança é produto do meio que vive, então é imprescindível um ambiente adequado." (Enfermeiro 6).

"'Tem que estar equilibrada para poder cuidar de toda uma demanda que uma criança pequena dá dentro de uma casa, pois a infraestrutura da família interfere muito no cuidado da criança." (Enfermeiro 2).

\section{Discussão}

O estudo revelou que o processo de trabalho do enfermeiro na Estratégia Saúde da Família (ESF), no que se refere à promoção dos vínculos familiares e desenvolvimento infantil, é composta por temas relacionados à atuação do enfermeiro no desenvolvimento infantil; e Percepção do enfermeiro sobre o cuidado e vínculos familiares dentro do seu contexto de trabalho.

Constatou-se que os enfermeiros durante a consulta de puericultura seguem um roteiro de acompanhamento da criança a partir das orientações preconizadas pelo Ministério da Saúde, reconhecendo como sua responsabilidade o acompanhamento e vigilância do desenvolvimento infantil.

A consulta de puericultura possui os objetivos de vigiar o crescimento físico e o desenvolvimento neuropsicomotor e intelectual; ampliar a cobertura vacinal; propiciar a educação alimentar e nutricional; promover a segurança e a prevenção de acidentes; promover a precaução de lesões intencionais, principalmente no ambiente doméstico; estimular a promoção da saúde e a prevenção das doenças mais comuns na comunidade; impulsionar a higiene física e mental e a prática de atividades de lazer adequadas às faixas etárias; propiciar a socialização, estimulação cultural e adaptação da criança e do adolescente em seu meio social (Del Ciampo et al, 2006).

A consulta em puericultura é voltada para os aspectos de prevenção e de promoção da saúde, atuando na manutenção da saúde da criança em seu pleno desenvolvimento (Brasil, 2012). Segundo Souza (2014), o desenvolvimento infantil é um processo ativo e único de cada criança, expresso por continuidade e mudanças nas habilidades motoras, cognitivas, psicossociais e de linguagem, com aquisições progressivamente mais complexas nas funções da vida diária e no exercício de seu papel social.

Um achado pelo presente estudo é a ausência do acompanhamento de crianças a partir de dois anos pelos enfermeiros nas consultas de puericultura, sem ações de promoção da saúde e vigilância do desenvolvimento infantil. Visto que Correia et al (2019) em estudo populacional no estado do Ceará, encontraram em seus achados que as crianças de 36-72 meses apresentavam maior prevalência de atrasos no desenvolvimento em todos os domínios quando comparadas àquelas menores de 36 meses. Esta questão, associada à precariedade das ações intersetoriais particularmente com creches e escolas, podem dificultar ações de promoção para o pleno desenvolvimento das crianças.

Uma vez que não existe a promoção da saúde e prevenção de agravos da forma adequada, há maior probabilidade da criança desenvolver ou mesmo exacerbar doenças evitáveis ou tratáveis, podendo resultar em danos que afetam o indivíduo durante a infância ou até na vida adulta (Assis, 2011). Considerando a complexidade do desenvolvimento da criança, esta temática deve integrar uma maior abrangência na vigilância de crianças acima de dois anos a fim de atuar na perspectiva de 
promoção da saúde.

O estudo constatou que os enfermeiros utilizam como instrumentos norteadores da avaliação do desenvolvimento, os protocolos do MS, a Caderneta de Saúde da Criança e os Prontuários Eletrônicos. Nenhum deles apontou utilizar brinquedos e objetos para avaliar o desenvolvimento. Para questões dos marcos do desenvolvimento que utilizam destes recursos, os profissionais questionam às mães o que não conseguem ver no momento da consulta. A percepção do cuidador sobre as potencialidades da criança é importante para a diligência do desenvolvimento infantil, porém considera-se a importância de insumos para a vigilância do cuidado infantil, nem sempre disponíveis na USF.

Uma revisão integrativa da literatura no estudo de Falbo et al (2012), teve como objetivo identificar as ações de enfermagem para estímulo ao desenvolvimento infantil. Os resultados apontam o lúdico como essencial ao desenvolvimento infantil, devendo ser explorado pela enfermagem por meio da arte, música, brinquedos e teatro. Orientar e intervir nos interrelacionamentos são ações de enfermagem para o desenvolvimento social e comportamental infantil. Os temas abordados na literatura são fundamentais para uma prática de enfermagem no cuidado integral à saúde da criança.

Considerando a relevância de brinquedos e instrumentos lúdicos para as ações de enfermagem, é indispensável que as políticas públicas considerem estes insumos enquanto instrumentos para o processo de trabalho do enfermeiro na atenção primária.

Identificou-se a percepção dos enfermeiros sobre a precariedade de vínculos existentes entre cuidadores-criança. Em contrapartida, foi relatado pelos entrevistados, o incentivo da promoção do desenvolvimento infantil através dos estímulos de práticas parentais positivas e cuidados afetivos ente pais e filhos no cotidiano, a partir do estímulo de brincadeiras, conversas, medidas lúdicas e participação do cuidador/integrante da família nas consultas. Dois dos entrevistados referiram que essa estimulação do vínculo familiar é feita desde o contato pré-natal.

O período pré-natal e os anos iniciais da infância são decisivos no processo de desenvolvimento, que é constituído pela interação das características biopsicológicas, herdadas geneticamente, e experiências oferecidas pelo meio ambiente. O alcance do potencial de cada criança depende do cuidado responsivo às suas necessidades de desenvolvimento (Brasil, 2012). Sendo assim, a relação enfermeiro - família é vista como o ponto chave para a potencialização do apoio familiar no desenvolvimento infantil.

De acordo com os enfermeiros, o enfoque ao aleitamento materno exclusivo constitui uma das principais orientações dos cuidados prestados nas consultas. Além de contribuir para o desenvolvimento do lactente, integra um dos laços mais emocionais entre mãe e filho. A amamentação constitui uma importante ligação afetiva que faz com que a mãe responda às necessidades do bebê e garanta que este possa estabelecer conexões futuras fundamentais. O contato estreito entre ambos estimula áreas do cérebro do bebê, determinantes para o seu desenvolvimento futuro (Brasil, 2018).

As atitudes que os pais exercem no cuidado com as crianças, como deixá-las na frente de um aparelho eletrônico (TV, tablet e telefones celulares), são percebidas como práticas rotineiras na sociedade contemporânea. Os entrevistados relataram que, muitas vezes os pais deixam os filhos no meio eletrônico como forma de alentar a distração das crianças diante da sobrecarga de atividades domésticas ou como recurso de distração para pais e crianças.

Em consequência disto, de acordo com os dados de uma pesquisa empírica realizada pela Secretaria Executiva da Rede Nacional da Primeira Infância (2014) sobre o tema "' O exagero de tecnologia deixa crianças e adolescentes desconectados do mundo real' evidenciaram que o uso excessivo dos aparelhos eletrônicos quando utilizados de maneira indiscriminada, trazem riscos para a saúde mental, física e social das crianças, pois substituem significativamente as atividades lúdicas tradicionais nas quais tem a capacidade de favorecer o incremento do relacionamento, afetividade e disciplina, uma vez que o contato físico promove a ampliação sinestésica e do desenvolvimento cognitivo (Paiva; Costa, 2015).

A dependência da tecnologia também provoca frustração entre as crianças, uma vez que, a necessidade por adquirir informações quantitativas causa intolerância e ansiedade, visto que os dispositivos apresentam 24 horas de acessibilidade. E 
nesse sentido, o uso indiscriminado descontrói o vínculo afetivo entre os membros da família, causando a ausência de referência de natureza emocional e dificultando o desenvolvimento cognitivo da criança (Paiva; Costa, 2015).

Segundo Papalia (2000), além dos aspectos da herança genética, o desenvolvimento infantil depende de situações de cuidado desde a sua concepção. As experiências infantis devem permitir-lhes se sentirem ouvidas, aceitas, cuidadas e amadas. De forma que tenham confiança em si próprias e lhes ofereçam subsídios para a sua formação pessoal e social. Destaca-se o papel da família como principal promotora desse cuidado e o enfermeiro, por sua vez, tem o poder da notariedade de estimular e incentivar estes vínculos.

Outro problema apontado no estudo é a sobrecarga do trabalho materno no cuidado à criança, tanto nas atividades domésticas, como no trabalho externo da mãe, muitas vezes em situações precárias e de desproteção legal.

A fragilidade no desempenho do papel dos pais, principalmente da mãe, por essa assumir grande parte dos cuidados com os filhos, visto que os homens se recusam a assumir ou participar mais ativamente do trabalho doméstico e da educação dos filhos, com o argumento de que são menos aptos para essas atividades e que lhes falta uma profunda relação com a criança (Martin; Angelo, 1996).

A mãe diante de todas essas responsabilidades acaba desempenhando o seu papel de forma frágil, sem reflexão e sem apoio. A mulher-mãe torna-se o eixo da estrutura familiar e tudo passa a ser alvo de seu controle: a criação e educação dos filhos, o cuidado com a casa, com a saúde dos membros da família e a necessidade de trabalhar (Martin; Angelo, 1996). A falta de suporte institucional para com o trabalho materno, particularmente, na oferta e acessos a creches, faz com que, na realidade estudada, este cuidado seja realizado por um vizinho ou outro cuidador.

A rede de apoio familiar constitui-se como uma instituição que desempenha papel relevante na vida social dos indivíduos, pois é no ambiente familiar que se promove a maior parte do cuidado com ações positivas que interferem na saúde dos sujeitos. Diante disso, a família é considerada um sistema em que os indivíduos interagem para o cuidado à saúde de seus membros, permeando-se por um conjunto de valores, crenças e conhecimentos que, envolvidos, promovem a proteção à saúde e a prevenção de doenças (Serapioni, 2005).

A revisão de literatura feita por Veerle et al (2013) apresenta efeitos protetores das redes sociais das famílias para a saúde e bem-estar das crianças. A coesão social entre vizinhanças pode promover processos sociais no ambiente familiar que contribuem positivamente para a melhoria da saúde das crianças e dos adolescentes. Portanto, potencializar o cuidado existente nas relações sociais das famílias e da comunidade pode contribuir para uma melhor qualidade de vida de seus integrantes, diminuir o desgaste em relação à saúde e promover o desenvolvimento infantil (Alexandre et al, 2012).

A participação do papel paterno foi identificada como relevante para os entrevistados, a partir da participação de alguns pais tanto durante o pré-natal, como nas consultas de puericultura. Porém, a falta de suporte do pai em relação ao cuidado com a criança e o resgate desse componente na realidade atual também foi mencionado como uma problemática ainda presente.

A influência da ausência paterna no desenvolvimento emocional, cognitivo e comportamental da criança e do adolescente evidencia as modificações na estrutura da família contemporânea, os efeitos negativos da ausência do pai e as repercussões decorrentes dessa ausência tanto nos aspectos comportamentais quanto nas vivências emocionais, produzindo variadas expressões de conflitos nos filhos sem apoio paterno (Eizirik; Bergmann, 2004).

A falta de abordagens para a criança pré-escolar também foi identificada pelo presente estudo, em que o vínculo de creches e escolas com as Unidades da Saúde da Família é acometido por contatos eventuais de ações e campanhas de vacinação e verminoses, tendo a questão do desenvolvimento infantil negligenciada. Para Lima e Bhering (2006), o ambiente escolar deve ser rico em recursos de estimulação ao desenvolvimento de linguagem, principalmente na fase pré-escolar, na qual a criança começa a desenvolver conhecimentos e capacidades importantes para o bom desempenho não apenas escolar, mas também social e emocional.

Ainda para Lima e Bhering (2006), as crianças estão sendo colocadas cada vez mais cedo e em um período maior de 
tempo em instituições de educação infantil, portanto é importante que o ambiente escolar também seja avaliado, de forma que esse possa oferecer as melhores condições possíveis para o desenvolvimento infantil. Nesse sentido, um vínculo intersetorial efetivo de Unidades de Saúde da Família com creches e escolas seria essencial para ações conjuntas e potenciais voltadas para o desenvolvimento infantil.

É nesse contexto que se situa o Programa Saúde na Escola (PSE), como consolidador da articulação saúde-educação. Instituído em 2007, resulta do trabalho integrado entre o Ministério da Saúde e o Ministério da Educação, na perspectiva de ampliar as ações específicas de saúde aos alunos da rede pública de ensino, contribuindo para a formação integral dos estudantes por meio de ações de prevenção, promoção e atenção à saúde. Dentre os principais objetivos, conta o fortalecimento do enfrentamento das vulnerabilidades, no campo da saúde, que possam comprometer o pleno desenvolvimento escolar e promover a comunicação entre escolas e unidades de saúde, assegurando a troca de informações sobre as condições de saúde dos estudantes (Brasil, 2007).

O processo de construção de ações intersetoriais voltadas para a promoção da saúde implica a troca e a construção coletiva de saberes, linguagens e práticas entre os diversos setores envolvidos na tentativa de equacionar questões sanitárias, produzindo soluções inovadoras para a melhoria da qualidade de vida de forma democrática e resolutiva. Desta forma, a intersetorialidade implica a existência de algum grau de abertura em cada setor envolvido para dialogar, estabelecendo vínculos de corresponsabilidade e cogestão pela melhoria da qualidade de vida da população (Campos; Barros; Castro, 2004).

Dentre as ações colaborativas voltadas para o desenvolvimento infantil identificadas pelo estudo, encontram-se os encaminhamentos para a Terapia Ocupacional do Núcleo de Apoio à Saúde da Família (NASF).

O terapeuta ocupacional do NASF objetiva prestar ações de promoção, proteção e recuperação da saúde das crianças, por meio de ações com participação da comunidade com uma atuação multiprofissional e com vistas à interdisciplinaridade, tendo como intuito: estimular o desenvolvimento de hábitos, comportamentos e atitudes voltadas à uma vida saudável e ao bemestar social; identificar e prevenir os problemas e riscos para a saúde, que afetam o processo de aprendizagem; e contribuir com ambientes propícios ao desenvolvimento físico, mental e social (Brasil, 2009).

Uma questão referida pelos enfermeiros como mais uma problemática, foi a percepção das condições socioeconômicas das famílias que interferem diretamente no cuidado familiar e no desenvolvimento das crianças. A gravidade do quadro de pobreza e miséria, no Brasil, constitui permanente preocupação e obriga a refletir sobre suas influências no social e, principalmente, na área de atuação junto da família (Gomes; Pereira, 2005).

Ainda para Gomes e Pereira (2005), pobreza não pode ser definida de forma única, mas ela se evidencia quando parte da população não é capaz de gerar renda suficiente para ter acesso sustentável aos recursos básicos que garantam uma qualidade de vida digna. Estes recursos são água, saúde, educação, alimentação, moradia, renda e cidadania. A situação socioeconômica é o fator que mais tem contribuído para a desestruturação da família, repercutindo diretamente e de forma vil nos mais vulneráveis desse grupo: os filhos, vítimas da injustiça social. A pobreza, a miséria, a falta de perspectiva de um projeto existencial que vislumbre a melhoria da qualidade de vida, impõe a toda a família uma luta desigual e desumana pela sobrevivência.

No presente estudo, os enfermeiros vislumbraram o papel que a situação socioeconômica tem sobre as relações entre cuidadores e crianças, particularmente nas situações que podem repercutir em negligência e violência.

Petrini (2003) afirma que à medida que a família encontra dificuldades para cumprir satisfatoriamente suas tarefas básicas de socialização e de amparo/serviços aos seus membros, criam-se situações de vulnerabilidade. A vida familiar para ser efetiva e eficaz depende de condições para sua sustentação e manutenção de seus vínculos.

A proteção integral à criança e ao adolescente, garantida pelo Estatuto da Criança e do Adolescente - ECA em seu art. $4^{\circ}$, que tem a família, além da comunidade, da sociedade e do Poder Público, como uma das responsáveis pela proteção da sua prole, se vê, no entanto, no rumo inverso, uma vez que, alijada das mínimas condições socioeconômicas, sofre o processo da exclusão social. A injustiça social dificulta o convívio saudável da família, favorecendo o desequilíbrio das relações e a 
desagregação familiar (Brasil, 1990; Gomes; Pereira, 2005).

Esses dados apontam a importância de se considerar o desenvolvimento infantil dentro do bem-estar geral da criança, de modo a envolver conhecimentos e cooperação entre diversos setores. Os enfermeiros como membros da equipe da Saúde da Família, assumem papel crucial na relação de vínculo e confiança com as famílias adstritas no território. Por outro lado, se veem sobrecarregados, carecendo de uso de estratégias de articulações intersetoriais que possam potencializar os vínculos familiares das famílias com as crianças.

\section{Conclusão}

O objetivo de estudo desse trabalho foi compreender a atuação do enfermeiro na promoção de vínculos familiares e desenvolvimento infantil. A partir da análise qualitativa dos dados, emergiram duas categorias que retratam as experiências envolvidas no presente estudo: atuação do enfermeiro no desenvolvimento infantil e percepção do enfermeiro sobre o cuidado e vínculos familiares.

Com base no que foi apresentado, os enfermeiros seguem as orientações preconizadas pelo Ministério da Saúde, reconhecendo como sua responsabilidade o acompanhamento e vigilância do desenvolvimento infantil. A Caderneta de Saúde da Criança foi identificada como principal instrumento no processo de trabalho do enfermeiro, sendo um parâmetro fundamental para detectar anormalidades e orientar os cuidadores.

Práticas parentais positivas, brincadeiras e conversas entre pais e filhos foram trazidas como estímulos dos enfermeiros nas consultas de puericultura e pré-natal, caracterizando a importância deste profissional como potencializador da promoção dos vínculos familiares. A questão do incentivo ao aleitamento materno e a participação do cuidador nas consultas também retratam as potencialidades do enfermeiro nesta temática. Esta abertura enfermeiro-cuidador é favorecida por meio de ajudas, apoios e conversas.

Porém, a relação entre criança e família é compreendida como precária na percepção dos enfermeiros entrevistados. Foram relatadas situações de negligência e violência. Além disso, entraves e fatores intrafamiliares como pouco envolvimento da rede familiar, sobrecarga materna, ausência paterna nos cuidados com a criança e fatores socioeconômicos foram evidenciados como aspectos que dificultam ainda mais a promoção dos vínculos familiares.

Somando-se a isso, foi identificada a fragilidade de ações potencializadoras do desenvolvimento infantil na USF. O acompanhamento do crescimento e desenvolvimento pelo enfermeiro é realizado apenas em crianças saudáveis de zero a dois anos. Constatou-se ainda que os enfermeiros não utilizam brinquedos e objetos para a avaliação dos marcos de desenvolvimento infantil em suas consultas, evidenciando a deficiência de insumos e a necessidade de uma maior abrangência na vigilância de crianças acima de dois anos a fim de atuar na perspectiva de promoção da saúde na atenção primária.

As ações em creches e instituições de ensino também são vistas como frágeis, em consequência do vínculo USF/escola ser composto por demandas eventuais de vacinação e campanhas de verminoses, sem a perspectiva de ações voltadas para a vigilância do desenvolvimento infantil.

Portanto, este trabalho evidencia as dificuldades inerentes à implementação de ações voltadas à promoção do desenvolvimento infantil, considerando fatores complexos ligados às famílias e seu contexto de vida, além da atuação dos enfermeiros como suporte e encorajamento a este processo.

Diante disso, aponta-se a sugestão de qualificação na formação dos enfermeiros que possibilite o raciocínio da importância do desenvolvimento infantil por meio da promoção dos vínculos familiares para assim, alcançar a resolutividade e integralidade do cuidado infantil. É preciso, no entanto, garantir o contato com este tema desde a formação acadêmica, por meio de disciplinas teóricas, trazendo também a humanização do cuidado. Visto também a deficiência deste tema em artigos brasileiros encontrados, torna-se relevante o incentivo de novos estudos desse porte a fim de abranger conhecimento para os enfermeiros 
que trabalham com essa população.

Ademais, processos de educação permanente devem ser desenvolvidos a partir da problematização da realidade de trabalho como fator principal para a construção de novos conhecimentos e estratégias de formas criativas, para serem aplicados em parceria com outros profissionais e setores, com compartilhamento de saberes e ações que considerem o protagonismo das famílias e crianças, a partir de fatores culturais e sociais que interferem diretamente em práticas do cuidado.

\section{Referências}

Abuchaim, et al. (2016). Importância dos vínculos familiares na primeira infância : estudo II / organização Comitê Científico do Núcleo Pela Infância. 1. ed. - São Paulo. Fundação Maria Cecilia Souto Vidigal - FMCSV.

Alexandre, A.M.C. et al. (2012). Map of the family social support netword for the promotion of child development. Revista Escola de Enfermagem. São Paulo, vol.46, n.2, pp.272-279. Disponível em: https://doi.org/10.1590/S0080-62342012000200002. Acesso em: 15 de set. 2020.

Assis, W.D. et al. (2011). Processo de trabalho da enfermeira que atua em puericultura nas unidades de saúde da família. Revista Brasileira de Enfermagem, v.64, n.1, p. 38-46.

Araújo, J. et al. (2014). História da saúde da criança: conquistas, políticas e perspectivas. Revista Brasileira de Enfermagem. dez; 67(6):1000-7.

Brasil (1986). Lei n. 7.498, de 25 de junho de 1986. Dispõe sobre a regulamentação do exercício da Enfermagem e dá outras providências. Brasília, DF.

Brasil (1990). Lei Federal n 8.069/90, de 13 de julho de 1990. Estatuto da Criança e do Adolescente. Ministério da Justiça, Brasília, DF.

Brasil (2007). Ministério da Saúde. Secretaria de Atenção à Saúde. Departamento de Atenção Básica. Política Nacional de Atenção Básica. 4. ed. Brasília, DF: MS.

Brasil (2007). Ministério da Saúde. Escolas promotoras de saúde: experiências do Brasil. Brasília, DF: Ministério da Saúde.

Brasil (2009). Ministério da Saúde. Secretaria de Atenção à Saúde. Departamento de Atenção Básica. Diretrizes do NASF. Brasília, DF: Ministério da Saúde. (Cadernos de Atenção Básica, n.27, série B. Textos Básicos de Saúde).

Brasil (2012). Ministério da Saúde. Secretaria de Atenção á Saúde. Saúde da criança: crescimento e desenvolvimento. Brasília: Ministério da Saúde. (Cadernos de Atenção Básica, n.33)

Brasil (2012). Resolução $n^{o} 466$, de 12 de dezembro de 2012. Dispõe sobre diretrizes e normas regulamentadoras de pesquisas envolvendo seres humanos. Brasília, DF.

Brasil (2015). Secretaria de Estado de saúde de São Paulo. Manual de acompanhamento da criança. São Paulo.

Brasil (2018). Ministério da Saúde. Política Nacional de Atenção Integral à Saúde da Criança: Orientações para implementação. Brasília, DF.

Brasil (2018). Ministério da saúde: Caderneta de Saúde da Criança. Brasília- DF.

Campos, R.M.C. et al. (2011). Consulta de enfermagem em puericultura: a vivência do enfermeiro na Estratégia de Saúde da família. Revista Escola de Enfermagem. USP. 45(3): 566-74.

Campos, G.W; Barros, R.B \& Castro, A.M. (2004). Avaliação de política nacional de promoção da saúde. Ciências e Saúde Coletiva. Rio de Janeiro, 9(3):745749 .

Cervo, A.L.; Bervian, \& Da Silva, P.A.R. (2007). Metodologia científica. 6. ed. São Paulo: Pearson.

Correia et al. (2019). Prevalence and socioeconomic determinants of development delay among children in Ceará, Brazil: A population-based study. Plos ONE, v.14, n.11.

Del Ciampo, L. A. et al. (2006). O Programa de Saúde da Família e a Puericultura. Ciência e Saúde Coletiva, v. 11, n. 3, p. 739-743.

Eizirik, M. \& Bergmann, D.V. (2014). Ausência paterna e sua repercussão no desenvolvimento da criança e do adolescente: um relato de caso. Revista de psiquiatria do Rio Grande do Sul. Porto Alegre, vol.26, n.3, dez.

Falbo, B.C.P, et al. (2012). Estímulo ao desenvolvimento infantil: produção do conhecimento em enfermagem. Revista Brasileira de Enfermagem. Brasília. $65(1): 148-54$.

Gomes, M.A \& Pereira, M.L.D. (2005). Família em situação de vulnerabilidade social: uma questão de políticas públicas. Ciências e Saúde Coletiva. Rio de Janeiro, v.1, n.2, abr/jun.

Lima, A.B.R; Bherring, E. (2006). Um estudo sobre creches como ambiente de desenvolvimento. Cadernos de Pesquisa. 26(129):573-96.

Martin, V.B.; Angelo, M. (1998). O significado do conceito saúde na perspectiva de famílias em situação de risco pessoal e social. Revista Latino-Americana de Enfermagem. Ribeirão preto, vol.6, no.5, dez.

Minayo, M.C.S. (2008). O desafio do conhecimento. 11 ed. São Paulo: Hucitec. 
Research, Society and Development, v. 10, n. 12, e481101220790, 2021

(CC BY 4.0) | ISSN 2525-3409 | DOI: http://dx.doi.org/10.33448/rsd-v10i12.20790

Paiva, N.M.N; Costa, JS. (2015). A influência da tecnologia na infância: Desenvolvimento ou Ameaça? Disponível em: https://www.psicologia.pt/artigos/textos/A0839.pdf. Acesso em: 26 de set.2020.

Papalia, D. E.; Olds, S. W. \& Feldman, R.D. (2000). Desenvolvimento humano. 7. ed. Porto Alegre: Artmed.

Petrini, J.C. (2003.) Pós-modernidade e família: um itinerário de compreensão. Bauru: Edusc.

SIAB. (2019). Sistema de Informação de Atenção Básica. 2012. Disponível em: https://sisab.saude.gov.br/. Acesso em: 20 de out.

Souza, J.M. (2014). Desenvolvimento infantil: análise de conceito e revisão dos diagnósticos da NANDA- I. Tese (Doutorado em Cuidado em Saúde). Escola de Enfermagem da Universidade de São Paulo. São Paulo.

Secretaria Executiva da Rede Nacional Primeira Infância. (2014). Exagero de tecnologia deixa crianças e adolescentes desconectados do mundo real. Disponível em: http://primeirainfancia.org.br/?p=17626. Acesso em: 12 de set. 2020

Serapioni, M. (2005). O papel da família e das redes primárias na reestruturação das políticas sociais. Ciências e saúde coletiva (Online). Rio de Janeiro, vol.10, pp.243-253, set./dez. . Disponível em: https://doi.org/10.1590/S1413-81232005000500025. Acesso em: 22 de set.

Veerle, V. et al. (2013). Does neighbourhood social capital aid in leveling the social gradient in the health and well-being of children and adolescents? A literature review. BMC Public Health.

YIN, R. K. (2016). Estudo de caso: planejamento e métodos. 4. Ed. Porto Alegre: Bookman. 